\title{
Evaluation of Nematicidal Activity of Streptomyces yatensis KRA-28 against Meloidogyne incognita
}

\author{
Eun-Jae Park ${ }^{1,2}$, Hyun-Jae Jang ${ }^{1}$, Chan Sun Park', Seung-Jae Lee ${ }^{1}$, Soyoung Lee ${ }^{1}$, \\ Kang-Hoon Kim ${ }^{1}$, Bong-Sik Yun ${ }^{2}$, Seung Woong Lee ${ }^{1 *}$, and Mun-Chual Rho ${ }^{1 *}$ \\ 'Immunoregulatory Materials Research Center, Korea Research Institute of Bioscience and Biotechnology (KRIBB), \\ Jeongeup 56212, Republic of Korea \\ ${ }^{2}$ Division of Biotechnology and Advanced Institute of Environment and Bioscience, College of Environmental and \\ Bioresource Sciences, Jeonbuk National University, Iksan 54596, Republic of Korea
}

\begin{abstract}
The root-knot nematode (Meloidogyne incognita) is an important pathogen in crop cultivation, however, few methods are available to control this parasitic roundworm. In this study, the nematicidal effects of approximately 30 Streptomyces strains isolated from soil samples of Mt. Naejang (Korea) were tested against Meloidogyne incognita, and the culture broth of the strains KRA24 and KRA-28 exhibited approximately $75 \%$ and $85 \%$ insecticidal activity, respectively, in in vitro assays. In in vivo pot experiments, these strains reduced the number of nematodes in the soil and the number of egg masses in the roots of red peppers. The two strains also survived in the presence of insecticidal agents ( 0.1 to $3.0 \%$ ) such as fosthiazate, ethoprophos and terbufos when they were used in parallel. The mixture of KRA-24 or KRA-28 culture broth and fosthiazate exhibited nematicidal effects that were similar to those observed when KRA-24 or KRA-28 were used alone. Our results clearly suggest that the Streptomyces strains KRA-24 and KRA-28 should be promoted as a biocontrol agent against Meloidogyne incognita.
\end{abstract}

Keywords: Meloidogyne incognita, Streptomyces yatensis KRA-28, Streptomyces misionensis KRA-24, biocontrol, nematicidal activity

Received: August 22, 2019 Accepted: February 27, 2020

First published online: March 27, 2020

*Corresponding authors S.W.L.

Phone: +82-63-570-5264 Fax: +82-63-570-5239 E-mail: Iswdoc@kribb.re.kr M.C.R.

E-mail: rho-m@kribb.re.kr

pISSN 1017-7825 elSSN 1738-8872

Copyright (C) 2020 by The Korean Society for Microbiology and Biotechnology

\section{Introduction}

The loss of agricultural products to root-knot nematodes has been increasing annually worldwide. Root-knot nematodes belong to the genus Meloidogyne and are one of the most important causes of damage to major cultivated crops (pepper, potato, sweet potato, tomato, okra, cabbage, lettuce, etc.) [1,2]. Larvae of root-knot nematodes initially infect the roots of various crops, including watermelons, tomatoes, and carrots, and subsequently produce egg masses on the roots, resulting in root dysfunction that reduces the efficiency of plant water and nutrient utilization [1]. Therefore, infection by root-knot nematodes can cause significant decreases in plant yields and survival as a result of stunted root growth, root necrosis, and from increased susceptibility to various plant diseases $[1,3]$. Root-knot nematodes are distributed worldwide, and $M$. incognita, $M$. arenaria, $M$. hapla, M. cruciani, M. javanica and M. hispanica have been reported in Korea [4], where they severely damage watermelon, melon, tomato and oriental melon crops [5].

In general, a variety of methods are used to limit Meloidogyne damage, including the development of resistant crops, the control of cultivation environments (improvement of soil and sterilization by sunlight), the treatment of plant diseases using chemical nematicides, and the biological control of root-knot nematodes using microorganisms or plant extracts [6-11]. Among these methods, the control of root-knot nematodes by chemical nematicides is most heavily relied upon because the use of resistant crop varieties and controlling cultivation environments are methods with lower efficacy. However, chemical agents, including fosthiazate, ethoprophos and terbufos, have severely deleterious effects on the environment, human health and beneficial microorganisms in soil [12]. Thus, interest in the development of new nematicidal agents that do not impact crops, farmers, consumers, or the environment is growing. Accordingly, the use of the culture broth or secondary metabolites of microorganisms as biological control agents is an effective alternative to using chemical nematicides for the management of plant diseases [13]. Furthermore, the broad spectrum of disease suppression activities of microorganisms and their secretions and the possibility of combining their use with other control methods may promote their increased usage. In particular, Streptomyces is the main genus of actinomycetes that has been found to be active against nematodes by antagonism or parasitism in many studies [13-15]. Kim et al. (2012) reported 
that Streptomyces cacaoi GY525, isolated from liquid compost containing crab shell powder, could parasitize eggs of M. incognita, inhibit the egg hatch, and kill second-stage juveniles (J2s) in vitro. Also, Ruanpanun et al. (2011) tested the nematicidal activity of Streptomyces sp. CMU-MH021 on second-stage juveniles of $M$. incognita, and reported that the strains inhibited the egg hatch and induced M. incognita larval mortality in vitro. Therefore, we selected Streptomyces strains and conducted studies to derive anti-nematode active strains for Meloidogyne incognita.

In the search for a biological agent to control root-knot nematodes, we isolated various Streptomyces strains from soil samples and tested their potential insecticidal activity against Meloidogyne incognita. Streptomyces yatensis strain KRA-28 exhibited the most robust insecticidal activity of the tested strains, and its nematicidal potential was evaluated through in vivo pot experiments using red pepper plants.

\section{Materials and Methods}

\section{Isolation of Streptomyces spp. from Soil}

Streptomyces spp. were isolated from soil samples obtained from Mt. Naejang in Korea. For each collected soil sample, $1 \mathrm{~g}$ of soil was pretreated in a $100^{\circ} \mathrm{C}$ oven for $1 \mathrm{~h}$ and then diluted in $100 \mathrm{ml}$ of a saline solution $(0.85 \%$ $\mathrm{NaCl})$. Five different dilutions $(1: 10,1: 100,1: 1,000,1: 10,000$, and 1:100,000) were prepared using saline solution, from which $0.1 \mathrm{ml}$ aliquots were plated on Bennett's agar medium [16] as a selective medium. The plates were incubated at $28^{\circ} \mathrm{C}$ for $96 \mathrm{~h}$, after which colonies were selected and transferred to fresh Bennett's agar medium. Isolated Streptomyces spp. were stored at $-80^{\circ} \mathrm{C}$ in $20 \%(\mathrm{v} / \mathrm{v})$ glycerol until use. For in vitro and in vivo experiments, the isolates were cultured on modified GSS medium ( $10 \mathrm{~g}$ soluble starch, $20 \mathrm{~g}$ dextrose, $4 \mathrm{~g}$ yeast extract, $1 \mathrm{~g}$ beef extract, $2 \mathrm{~g} \mathrm{NaCl}, 0.25 \mathrm{~g} \mathrm{~K}_{2} \mathrm{HPO}_{4}, 2 \mathrm{~g} \mathrm{CaCO}_{3}$, and $25 \mathrm{~g}$ defatted soybean powder, w/v) at $28^{\circ} \mathrm{C}$ for $72 \mathrm{~h} \mathrm{[15].}$

\section{Identification of Isolated Strains}

A 16 S ribosomal RNA sequencing analysis was performed according to the manufacturer's protocol (Genotech Co., Korea). DNA extracted from actinomycetes using a Genomic Cell/Tissue Spin Mini Kit according to the manufacturer's instructions (Nucleogen). The 16S rRNA gene was amplified by PCR using two universal primers, 9F (5'-GAGTTTGATCCTGGCTCAG-3') and 1512R (5'-ACGGTTACCTTGTTACGACTT-3'), which were sequenced using an ABI Prism 3730xi Sequencer. The 16S ribosomal RNA gene sequences were compared with those in the GenBank database using the program BLAST.

\section{Nematode Culturing}

Meloidogyne incognita was obtained from egg masses on the roots of red pepper plants (Capsicum annuum cv. Bugang) using the method of Moon et al. (2010) [17]. First, red pepper plants grown for 4 weeks were infected with 1,000 Meloidogyne incognita juveniles, which were obtained from Prof. Young Ho Kim (Seoul National University, Korea). After 60 days, the plants were uprooted from pots, washed with flowing water, and the egg masses on the roots were harvested. The egg masses were incubated in sterile water for three days at r.t. in a Baermann funnel, and the hatched second-stage juveniles (J2s) were subsequently harvested and used for nematicidal activity and in vivo pot experiments.

\section{Nematicidal Activity}

The nematicidal activity of the culture broth from each strain was determined using the J2s [18]. A fresh suspension of $\mathrm{J} 2 \mathrm{~s}(100 \mathrm{~J} 2 \mathrm{~s} / 100 \mu \mathrm{l})$ was added to the wells of a 96-well plate and treated with culture broth at concentrations of $10,5,3$, and $1 \%$. Sterilized GSS broth or sterile distilled water was used as negative control. Five replicates were performed for each culture broth. The plates were incubated at $25^{\circ} \mathrm{C}$ for $24 \mathrm{~h}$, and the number of living and dead juveniles were counted using a microscope at 6,12 , and $24 \mathrm{~h}$. The experiment was performed with five replicates. Mortality was calculated according to the following formula: juvenile mortality $=100 \times$ dead juveniles/total juveniles.

\section{Survival Test}

We also conducted experiments to confirm whether the isolated strains could survive on Bennett's medium containing anti-nematode agents, such as fosthiazate (Seonchungtan, Korea), ethoprophos (Mocap, Korea) and terbufos (Kaunta, Farm Hannong, Korea). After the concentration of anti-nematode agents in Bennett's medium was adjusted to $0.1-5 \%$, the isolated strains were inoculated at a concentration of $1.5 \times 10^{2}$ cells $/ \mathrm{ml}$. The flasks were incubated at $28^{\circ} \mathrm{C}$ for $72 \mathrm{~h}$, and the growth of the strains was measured. Next, $0.1 \mathrm{ml}$ of culture medium was spread on Bennett's agar plates; the inoculated plates were then incubated at $28^{\circ} \mathrm{C}$ for $96 \mathrm{~h}$, and the colonies grown were counted. The experiment was performed with five replicates.

\section{In Vivo Effect of KRA-24 and KRA-28 in Pot Experiments}

In vivo pot experiments were conducted to investigate the antagonistic activity of Streptomyces misionensis KRA-24 and Streptomyces yatensis KRA-28 on Meloidogyne incognita. The experiments were performed in a controllable greenhouse that was maintained at $25 \pm 2^{\circ} \mathrm{C}$ and $60 \pm 2 \%$ humidity with a $12 \mathrm{~h}$ light and dark cycle. Red pepper seeds were planted in pots containing nursery soil (Bunong horticulture nursery soil, Korea). Twoweek-old red pepper seedlings were transplanted into plastic pots with a $6-\mathrm{cm}$ diameter containing $500 \mathrm{~g}$ of sterilized sand and potting mixture. After the plants were cultivated for four weeks, they were inoculated with approximately 1000 M. incognita J2s [19]. Four weeks after inoculation, the J2s-infected plants were divided into 7 groups, and each group was given a different treatment. Group 1: each plant was inoculated with GSS medium 
without microbial cultures. Groups 2 and 3: each plant was treated with $100 \mathrm{ml}$ of a 10-fold dilution of culture broths of S. misionensis KRA-24 or S. yatensis KRA-28, which was repeated every 2 weeks. Group 4: each plant was treated with $100 \mathrm{ml}$ of an aqueous solution containing $9.5 \mathrm{mg}$ of an anti-nematode agent, and these plants served as a positive control. Groups 5 and 6: each plant was inoculated with $100 \mathrm{ml}$ of anti-nematode solution and $100 \mathrm{ml}$ of the 10-fold diluted culture broths of S. misionensis KRA-24 and S. yatensis KRA-28. Group 7: each uninfected plant was treated with $100 \mathrm{ml}$ of water, and these plants served as a negative control. Each pot experiment was replicated five times. Plants were watered using $100 \mathrm{ml} /$ pot every 4 days, and after 30 and 60 days, the length and dry weight of roots and shoots, the number of egg masses on roots, and the number of nematodes in the soil were measured.

The number of egg masses on roots was determined using the phloxine B staining method [20]. In addition, the number of bacteria, including actinomycetes, in the soil was determined using the modified funnel method [21]. Briefly, $1 \mathrm{~g}$ of soil was diluted 10 -fold with a $0.85 \% \mathrm{NaCl}$ solution, after which the mixture was plated on LB agar plates. The plates were incubated for 2 days at $30^{\circ} \mathrm{C}$, and the number of colonies was subsequently determined. In the case of actinomycetes, $1 \mathrm{~g}$ of soil was heated at $100^{\circ} \mathrm{C}$ for $1 \mathrm{~h}$ and then diluted 10 -fold in $0.85 \% \mathrm{NaCl}$. The diluted mixture was then plated on Bennett's medium agar plates and incubated at $28^{\circ} \mathrm{C}$ for 4 days, and the number of colonies were then counted.

\section{Data Analysis}

Statistical analyses were performed using one-way analysis of variance, and the means of the treatments were determined by Duncan's multiple-range test $(p<0.05)$ using SPSS (version 16.0 for Windows; SPSS, USA).

\section{Results}

\section{Selection of Anti-Nematode Strains}

Thirty Streptomyces strains isolated from soil samples of Mt. Naejang in Korea were tested for anti-nematode activity against Meloidogyne incognita. M. incognita J2s were treated with the culture broths of the 30 isolated strains at a concentration of $10 \%$, and the viability of the $\mathrm{J} 2 \mathrm{~s}$ was determined after a $48 \mathrm{~h}$ incubation. Among the isolated strains, the culture broths of nine strains caused over 50\% mortality of J2s. As shown in Fig. 1, an $85.9 \pm$ $2.3 \%$ mortality of $\mathrm{J} 2 \mathrm{~s}$ was observed in the group treated with culture broth of the KRA-28 strain, and for the group treated with the KRA-24 strain, a $75.9 \pm 3.1 \%$ mortality of J2s was observed. For the KRA-5, KRA-7, KRA-10 and KRA- 11 culture broths, the observed mortality of J2s was $65.2 \pm 3.6 \%, 62.3 \pm 1.3 \%, 64.5 \pm 1.9 \%$, and $64.8 \pm 2.8 \%$, and for the groups treated with KRA-1, KRA-2 and KRA- 4 culture broths the number of J2s was reduced by $54.5 \pm$ $2.3 \%, 56.7 \pm 1.7 \%$, and $56.4 \pm 3.4 \%$ (Fig. 1 ).

To further determine the larvicidal potential of biocontrol agents, we tested different concentrations of culture broths from strains KRA-24 and KRA-28 against $M$. incognita J2s. The mortality rate of J2s treated with KRA-28 culture broth scaled in a dose-dependent manner, increasing from $43.9 \pm 3.5$ to $86.3 \pm 2.7 \%$ as the concentration of culture broth increased from 1 to $10 \%$ (Fig. 2). The J2s were also significantly affected by KRA-24 culture broth, which induced mortalities of $38.3 \pm 2.6,53.2 \pm 2.8,63.9 \pm 2.4$, and $78.9 \pm 2.5 \%$ at concentrations of $1,3,5$, and $10 \%$, respectively, after a period of $48 \mathrm{~h}$. Thus, the KRA-28 strain culture broth showed an approximately $10 \%$ greater anti-nematode activity in the larvicidal assay than that of the KRA-24 strain (Fig. 2). KRA-28 strain was identified as Streptomyces yatensis KRA-28, with closest $16 \mathrm{~S}$ rDNA sequence identity (99\%) to that of the type strain Streptomyces yatensis strain DSM 41771 by analyzing their 16 S ribosomal RNA gene sequences. KRA-24 strain was identified as Streptomyces misionensis KRA-24.

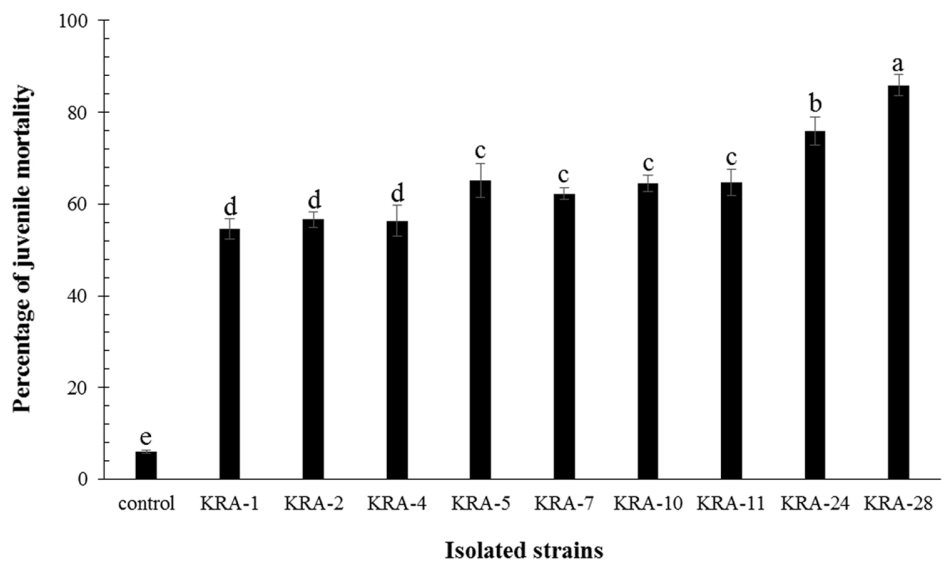

Fig. 1. In vitro nematicidal activity of nine isolated strains. The experiment was performed with five replicates. Water was used as the control. Values with the same letter on the bar do not significantly differ $(p<0.05)$ based on Duncan's multiple range test. 


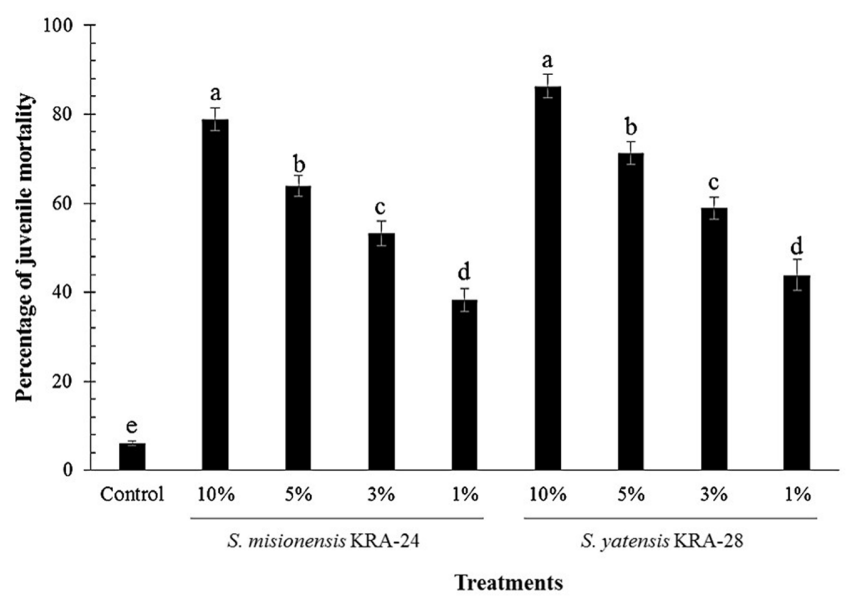

Fig. 2. In vitro nematicidal effect of Streptomyces misionensis KRA-24 and Streptomyces yatensis KRA-28. Plants were treated with culture supernatants at concentrations of $10,5,3$, and $1 \%$. The experiment was performed with five replicates. Water was used as the control. Values with the same letter on the bar do not significantly differ $(p<0.05)$ based on Duncan's multiple range test.

Viability of the KRA-24 and KRA-28 Strains in Medium Containing Anti-Nematode Agents

To assess whether S. misionensis KRA-24 and S. yatensis KRA-28 could be used as biocontrol agents in the field, we measured the viabilities of these strains in medium containing insecticides, such as fosthiazate (Seonchungtan), ethoprophos (Mocap) and terbufos (Kaunta), which are marketed as anti-nematode agents in Korea. Each strain was inoculated with $1.5 \times 10^{2}$ in Bennett's medium containing $0.1-5.0 \%$ insecticide and incubated at $28^{\circ} \mathrm{C}$ for $72 \mathrm{~h}$. As shown in Table 1, the growth of two strains was not affected at insecticide concentrations of $0.1-0.15 \%$, which are the recommended concentrations for use of these agents. In addition, the two strains grew in the range of $10^{2}-10^{4}$ in the presence of $0.5-3.0 \%$ fosthiazate, ethoprophos and terbufos, but not at $5 \%$.

\section{Effects of KRA-24 and KRA-28 on Plant Growth and the Number of Nematodes and Egg Masses}

Pot experiments were carried out to further assess the in vivo biocontrol efficacy of S. misionensis KRA-24 and S. yatensis KRA-28 and to select a strain for use in the field. The red pepper seedlings were planted in pots and then infected with J2s for four weeks. After the plants were confirmed to be infected with M. incognita, culture broths of the strains KRA-24 and KRA-28 were applied to the plant at $100 \mathrm{ml} /$ pot every two weeks. After 60 days, the length and dry weight of shoots were $28.4 \pm 1.1 \mathrm{~cm}$ and $0.65 \pm 0.04 \mathrm{~g}$, respectively, whereas in the control (only infected

Table 1. Insecticide resistance of $S$. misionensis KRA-24 and S. yatensis KRA-28. ${ }^{\mathrm{a}}$

\begin{tabular}{|c|c|c|c|}
\hline Treatment $^{\mathrm{b}}$ & Concentration $(\%)^{\mathrm{c}}$ & KRA-24 & KRA-28 \\
\hline Control & 0 & $2.1 \times 10^{5} \mathrm{a}^{\mathrm{d}}$ & $3.1 \times 10^{5} \mathrm{a}$ \\
\hline \multirow[t]{5}{*}{ Fosthiazate } & 0.1 & $1.7 \times 10^{5} \mathrm{~b}$ & $2.1 \times 10^{5} \mathrm{~b}$ \\
\hline & 0.5 & $3.2 \times 10^{4} \mathrm{c}$ & $4.1 \times 10^{4} \mathrm{c}$ \\
\hline & 1.0 & $1.2 \times 10^{4} \mathrm{cb}$ & $8.2 \times 10^{3} \mathrm{~cd}$ \\
\hline & 3.0 & $3.2 \times 10^{3} \mathrm{~d}$ & $2.1 \times 10^{2} \mathrm{~d}$ \\
\hline & 5.0 & $-e$ & - \\
\hline \multirow[t]{5}{*}{ Ethoprophos } & 0.15 & $1.7 \times 10^{5} \mathrm{a}$ & $2.1 \times 10^{5} \mathrm{~b}$ \\
\hline & 0.5 & $2.4 \times 10^{4} b$ & $4.2 \times 10^{4} \mathrm{c}$ \\
\hline & 1.0 & $5.2 \times 10^{3} \mathrm{c}$ & $8.9 \times 10^{3} \mathrm{~d}$ \\
\hline & 3.0 & $8.6 \times 10^{2} \mathrm{c}$ & $4.1 \times 10^{2} \mathrm{~d}$ \\
\hline & 5.0 & - & - \\
\hline \multirow[t]{5}{*}{ Terbufos } & 0.1 & $1.6 \times 10^{5} \mathrm{a}$ & $7.8 \times 10^{4} \mathrm{~b}$ \\
\hline & 0.5 & $5.1 \times 10^{4} \mathrm{~b}$ & $2.6 \times 10^{4} \mathrm{c}$ \\
\hline & 1.0 & $2.4 \times 10^{4} \mathrm{c}$ & $4.1 \times 10^{3} \mathrm{~d}$ \\
\hline & 3.0 & $3.2 \times 10^{3} \mathrm{c}$ & $2.2 \times 10^{2} \mathrm{~d}$ \\
\hline & 5.0 & - & - \\
\hline
\end{tabular}

a The strains were inoculated with $1.5 \times 10^{2}$ in Bennett's medium containing anti-nematode agents. After the bacteria were incubated at $28^{\circ} \mathrm{C}$ for $72 \mathrm{~h}$, their growth was measured. The experiment was performed with five replicates.

${ }^{\mathrm{b}}$ Fosthiazate: Seonchungtan; Ethoprophos: Mocap; Terbufos: Kaunta; Control: no treatment.

'This column refers to the concentrations of anti-nematode agents in the Bennett's medium.

${ }^{\mathrm{d}}$ Values with the same letter in a column do not significantly differ $(p<0.05)$ based on Duncan's multiple range test.

${ }^{\mathrm{e}}$ Microorganisms were not detected. 
Table 2. Mean growth characteristics of red pepper plants treated with S. misionensis KRA-24 and S. yatensis KRA-28 in pot experiments. ${ }^{\text {a }}$

\begin{tabular}{|c|c|c|c|c|c|c|c|c|}
\hline \multirow[b]{2}{*}{ Treatment $^{\mathrm{b}}$} & \multicolumn{4}{|c|}{30 days } & \multicolumn{4}{|c|}{60 days } \\
\hline & $\begin{array}{l}\text { Root length } \\
(\mathrm{cm})\end{array}$ & $\begin{array}{l}\text { Shoot length } \\
(\mathrm{cm})\end{array}$ & $\begin{array}{c}\text { Dry root } \\
\text { weight }(\mathrm{g})\end{array}$ & $\begin{array}{l}\text { Dry shoot } \\
\text { weight }(\mathrm{g})\end{array}$ & $\begin{array}{l}\text { Root length } \\
(\mathrm{cm})\end{array}$ & $\begin{array}{l}\text { Shoot length } \\
(\mathrm{cm})\end{array}$ & $\begin{array}{c}\text { Dry root } \\
\text { weight (g) }\end{array}$ & $\begin{array}{l}\text { Dry shoot } \\
\text { weight }(\mathrm{g})\end{array}$ \\
\hline ontrol & $18.8 \pm 0.8 \mathrm{a}^{\mathrm{c}}$ & $24.4 \pm 1.5 \mathrm{c}$ & $0.17 \pm 0$. & $0.57=$ & $20.1 \pm$ & $28.4 \pm 1.1 \mathrm{~b}$ & $01 \mathrm{a}$ & 0.65 \\
\hline KRA-24 & $18.6 \pm$ & $28.6 \pm 1.1 \mathrm{ab}$ & 0.17 & 0.66 & & $3 \mathrm{ab}$ & $1 \mathrm{~b}$ & 0.6 \\
\hline KRA-28 & $19.0 \pm 0.7 \mathrm{a}$ & $29.2 \pm 1.3 \mathrm{a}$ & $0.17 \pm 0.01 \mathrm{cb}$ & $0.78 \pm 0.03 \mathrm{a}$ & $22.0 \pm 1.6 b$ & $32.8 \pm 2.4 \mathrm{a}$ & $0.22 \pm 0.03 \mathrm{ab}$ & 0.83 \\
\hline $\mathrm{F}$ & $18.6 \pm 1.1 \mathrm{a}$ & $27.2 \pm 1.6 \mathrm{ab}$ & $0.16 \pm 0.02 c$ & $0.52 \pm 0.09 c$ & $20.0 \pm 1.5 b$ & $32.2 \pm 0.8 \mathrm{a}$ & $0.15 \pm 0.02 c$ & $0.47 \pm 0.05 \mathrm{e}$ \\
\hline $\mathrm{F}+\mathrm{KRA}-24$ & $10.0 \pm 2.9 \mathrm{a}$ & $28.6 \pm 1.8 \mathrm{ab}$ & $0.19 \pm 0.01 \mathrm{a}$ & $0.65 \pm 0.05 b$ & $21.1 \pm 2.6 b$ & $30.1 \pm 2.5 \mathrm{ab}$ & $0.20 \pm 0.03 \mathrm{ab}$ & $0.74 \pm 0.05 \mathrm{c}$ \\
\hline $\mathrm{F}+\mathrm{KRA}-28$ & $18.4 \pm 2.1 \mathrm{a}$ & $28.0 \pm 1.5 \mathrm{ab}$ & $0.18 \pm 0.02 \mathrm{ab}$ & $0.69 \pm 0.05 b$ & $22.4 \pm 2.7 b$ & $31.4 \pm 4.5 \mathrm{ab}$ & $0.21 \pm 0.03 \mathrm{ab}$ & $0.76 \pm 0.07 \mathrm{c}$ \\
\hline $\mathrm{H}_{2} \mathrm{O}^{\mathrm{d}}$ & $19.6 \pm 1.1 \mathrm{a}$ & $26.6 \pm 1.7 \mathrm{~b}$ & $0.17 \pm 0.01 \mathrm{cb}$ & $0.83 \pm 0.02 \mathrm{a}$ & $31.8 \pm 2.4 \mathrm{a}$ & $32.8 \pm 2.2 \mathrm{a}$ & $0.21 \pm 0.01 \mathrm{ab}$ & $0.92 \pm 0.03 \mathrm{a}$ \\
\hline
\end{tabular}

${ }^{\mathrm{a}}$ Each pot was watered using $100 \mathrm{ml} /$ pot every 4 days, and culture broths were applied to plants at $100 \mathrm{ml} /$ pot every 2 weeks. After 30 and 60 days, the length and dry weight of roots and shoots were measured.

${ }^{\mathrm{b}}$ Control: treatment with GSS medium without microbial culture; KRA-24 and KRA-28: treatment with culture broth of $S$. misionensis KRA-24 and S. yatensis KRA-28; F: treatment of fosthiazate; F+KRA-24 and F+KRA-28: combination of fosthiazate and KRA- 24 or KRA- 28 .

'Values with the same letter in a column do not significantly differ $(p<0.05)$ based on Duncan's multiple range test.

${ }^{\mathrm{d}}$ The plants were not infected with J2s and were only treated with water.

$\mathrm{J} 2 \mathrm{~s}$ ) and negative control groups (treated only with $\mathrm{H}_{2} \mathrm{O}$ ), these values were $32.8 \pm 2.2 \mathrm{~cm}$ and $0.92 \pm 0.03 \mathrm{~g}$. The group treated with the culture broth of strain KRA-28 exhibited a greatly enhanced shoot length $(4.4 \mathrm{~cm})$ and dry weight $(0.18 \mathrm{~g})$. In addition, treatment of plants with the culture broth of strain KRA-24 increased the shoot length by nearly $1.6 \mathrm{~cm}$, resulting in similar dry weight values to those observed in the infected control group. However, the root length and dry weight of red pepper plants in the group treated with KRA-24 and KRA-28 did not increase significantly. The results indicated that all treatments increased the length and dry weight of shoots, and these data are presented in Table 2.

As shown in Table 3, all treatments significantly reduced the number of juveniles and egg masses at 30 and 60 days after inoculation compared to the values observed for the infected control group (infected only with J2s). After 60 days, the number of nematodes and egg masses in the infected control group increased, totaling $1836 \pm$ 84.4 nematodes and $142.8 \pm 5.3$ egg masses. The greatest reduction in the number of egg masses (total of $42.2 \pm 4.8$ egg masses) and the population of nematodes (total of $542 \pm 48.2$ nematodes) was observed when the culture broth of strain KRA-28 was applied (Table 3). Additionally, compared with that of strain KRA-28, the culture broth of strain KRA-24 moderately reduced the number of egg masses (total of $73.8 \pm 4.6$ egg masses) and the nematode population in soil (total of $644 \pm 32.9$ nematodes) (Table 3 ).

\section{Effects of Using a Combination of KRA-24 or KRA-28 and Anti-nematode Agent}

Experiments were conducted to determine whether $S$. misionensis KRA-24 and S. yatensis KRA-28 could be applied to soil containing pesticides. After red pepper plants were treated with fosthiazate and cultures of KRA-24 or KRA-28, the changes in the roots and shoots of crops and the number of nematodes in soil and egg masses on roots were measured. After 60 days (Table 2), the shoot length of the group treated with fosthiazate had increased by $3.8 \mathrm{~cm}$, however, the dry weights of the shoots and roots of plants in this group were reduced by $0.15 \pm 0.02 \mathrm{~g}$ and $0.47 \pm 0.05 \mathrm{~g}$, respectively. These results showed that the recommended usage of this agent $(0.1 \%)$ affected the growth of crops. The number of nematodes (total of $492 \pm 135.9$ nematodes) and egg masses (total of $14.4 \pm 3.9 \mathrm{egg}$ masses) of the group treated with fosthiazate was reduced by 73.2 and $89.9 \%$ compared with the control group

Table 3. Occurrence and propagation of Meloidogyne incognita in red pepper root and soil in pot experiments.

\begin{tabular}{|c|c|c|c|c|c|}
\hline \multirow[b]{2}{*}{ Treatment $^{\mathrm{a}}$} & \multirow{2}{*}{$\begin{array}{c}1 \text { day } \\
\begin{array}{l}\text { No. of inoculated } \\
\text { juveniles }\end{array}\end{array}$} & \multicolumn{2}{|c|}{30 days } & \multicolumn{2}{|c|}{60 days } \\
\hline & & $\begin{array}{c}\text { Juveniles } \\
\text { per } 100 \mathrm{~g} \text { soil }\end{array}$ & $\begin{array}{l}\text { Egg masses } \\
\text { per root }^{b}\end{array}$ & $\begin{array}{c}\text { Juveniles } \\
\text { per } 100 \mathrm{~g} \text { soil }\end{array}$ & $\begin{array}{l}\text { Egg masses } \\
\text { per root }\end{array}$ \\
\hline Control & $1032 \pm 74.6 \mathrm{a}^{\mathrm{c}}$ & $1286 \pm 56.4 \mathrm{a}$ & $84.8 \pm 5.8 \mathrm{a}$ & $1836 \pm 84.4 \mathrm{a}$ & $142.8 \pm 5.3 \mathrm{a}$ \\
\hline KRA-24 & $1006 \pm 34.4 \mathrm{a}$ & $520 \pm 91.4 b$ & $62.6 \pm 8.5 b$ & $644 \pm 32.9 b$ & $73.8 \pm 4.6 b$ \\
\hline KRA-28 & $1018 \pm 63.4 \mathrm{a}$ & $360 \pm 57.9 c$ & $50.02 \pm 4.8 c$ & $542 \pm 48.2 \mathrm{bc}$ & $42.2 \pm 4.8 c$ \\
\hline $\mathrm{F}$ & $996 \pm 24.1 \mathrm{a}$ & $294 \pm 113.9 \mathrm{~cd}$ & $6.8 \pm 2.6 \mathrm{~d}$ & $492 \pm 135.9 c$ & $14.4 \pm 3.9 \mathrm{~d}$ \\
\hline $\mathrm{F}+\mathrm{KRA}-24$ & $996 \pm 20.7 \mathrm{a}$ & $272 \pm 83.5 \mathrm{~cd}$ & $6.2 \pm 3.6 \mathrm{~d}$ & $504 \pm 118.0 c$ & $15.8 \pm 3.1 \mathrm{~d}$ \\
\hline $\mathrm{F}+\mathrm{KRA}-28$ & $1004 \pm 81.4 \mathrm{a}$ & $240 \pm 50.0 \mathrm{~d}$ & $6.4 \pm 2.1 \mathrm{~d}$ & $490 \pm 80.6 c$ & $10.08 \pm 3.4 \mathrm{~d}$ \\
\hline $\mathrm{H}_{2} \mathrm{O}^{\mathrm{d}}$ & - & - & - & - & - \\
\hline
\end{tabular}

${ }^{a}$ Control: treatment with GSS medium without microbial culture; KRA-24 and KRA-28: treatment with culture broth of S. misionensis KRA-24 and S. yatensis KRA-28; F: treatment of fosthiazate; F+KRA-25 and F+KRA-28: combination of fosthiazate and KRA-24 or KRA-28.

${ }^{\mathrm{b}}$ The number of egg masses on roots was determined using the Phloxine B staining method.

${ }^{c}$ Values with the same letter in a column do not significantly differ $(p<0.05)$ based on Duncan's multiple range test.

${ }^{\mathrm{d}}$ The plants were not infected with $\mathrm{J} 2 \mathrm{~s}$ and were only treated with water.

${ }^{\mathrm{e}}$ Juveniles were not detected. 
Table 4. The change in microorganism abundances in soil. ${ }^{\text {a }}$

\begin{tabular}{|c|c|c|c|c|c|c|}
\hline \multirow[b]{2}{*}{ Treatment ${ }^{b}$} & \multicolumn{2}{|c|}{1 day before treatment $c$} & \multicolumn{2}{|c|}{30 days } & \multicolumn{2}{|c|}{60 days } \\
\hline & $\begin{array}{c}\text { Total bacteria } \\
\text { per } 1 \mathrm{~g} \text { soil }\end{array}$ & $\begin{array}{c}\text { Actinomycetes } \\
\text { per } 1 \text { g soil }\end{array}$ & $\begin{array}{c}\text { Total bacteria } \\
\text { per } 1 \mathrm{~g} \text { soil }\end{array}$ & $\begin{array}{c}\text { Actinomycetes } \\
\text { per } 1 \mathrm{~g} \text { soil }\end{array}$ & $\begin{array}{c}\text { Total bacteria } \\
\text { per } 1 \mathrm{~g} \text { soil }\end{array}$ & $\begin{array}{c}\text { Actinomycetes } \\
\text { per } 1 \text { g soil }\end{array}$ \\
\hline Control & $4.9 \pm 0.9 \times 10^{3} \mathrm{a}^{\mathrm{d}}$ & $-{ }^{e}$ & $6.2 \pm 1.3 \times 10^{4} \mathrm{a}$ & - & $6.7 \pm 2.5 \times 10^{5} \mathrm{a}$ & - \\
\hline KRA-24 & $4.0 \pm 2.2 \times 10^{3} \mathrm{a}$ & - & $2.6 \pm 1.3 \times 10^{3} \mathrm{c}$ & $5.0 \pm 1.7 \times 10^{3} \mathrm{a}$ & $3.6 \pm 2.0 \times 10^{4} \mathrm{~b}$ & $5.1 \pm 0.9 \times 10^{4} \mathrm{~b}$ \\
\hline KRA-28 & $5.4 \pm 1.1 \times 10^{3} \mathrm{a}$ & - & $2.9 \pm 1.2 \times 10^{3} \mathrm{c}$ & $7.0 \pm 1.9 \times 10^{3} \mathrm{a}$ & $6.5 \pm 2.9 \times 10^{4} \mathrm{~b}$ & $7.1 \pm 0.9 \times 10^{4} \mathrm{ab}$ \\
\hline $\mathrm{F}$ & $4.6 \pm 1.8 \times 10^{3} \mathrm{a}$ & - & $3.9 \pm 1.9 \times 10^{2} \mathrm{c}$ & - & $5.8 \pm 3.4 \times 10^{3} \mathrm{~b}$ & - \\
\hline $\mathrm{F}+\mathrm{KRA}-24$ & $5.2 \pm 2.0 \times 10^{3} \mathrm{a}$ & - & $5.4 \pm 3.9 \times 10^{2} \mathrm{c}$ & $5.9 \pm 1.6 \times 10^{3} \mathrm{a}$ & $2.4 \pm 1.2 \times 10^{3} \mathrm{~b}$ & $7.0 \pm 2.5 \times 10^{4} \mathrm{ab}$ \\
\hline $\mathrm{F}+\mathrm{KRA}-28$ & $4.3 \pm 1.5 \times 10^{3} \mathrm{a}$ & - & $6.2 \pm 2.6 \times 10^{2} \mathrm{c}$ & $7.2 \pm 0.7 \times 10^{3} \mathrm{a}$ & $2.9 \pm 1.3 \times 10^{3} b$ & $8.3 \pm 1.2 \times 10^{4} \mathrm{a}$ \\
\hline $\mathrm{H}_{2} \mathrm{O}$ & $4.3 \pm 2.1 \times 10^{3} \mathrm{a}$ & - & $2.7 \pm 1.5 \times 10^{4} \mathrm{~b}$ & - & $6.7 \pm 1.5 \times 10^{4} \mathrm{~b}$ & - \\
\hline
\end{tabular}

The number of bacteria in the soil, including actinomycetes, was determined using the modified funnel method.

${ }^{b}$ Control: treatment with GSS medium without microbial culture; KRA-24 and KRA-28: treatment with culture broth of S. misionensis KRA-24 and S. yatensis KRA-28; F: treatment of fosthiazate; F+KRA-25 and F+KRA-28: combination of fosthiazate and KRA-24 or KRA-28.

${ }^{c}$ The number of microorganisms before treatment with S. misionensis KRA-24 and S. yatensis KRA-28 culture broth.

${ }^{\mathrm{d}}$ Values with the same letter in a column do not significantly differ $(p<0.05)$ based on Duncan's multiple range test.

${ }^{\mathrm{e}}$ Actinomycetes were not detected.

infected with J2s, respectively (Table 3). As shown in Table 3, the combined use of fosthiazate and KRA-24 or KRA28 reduced the number of nematodes and egg masses by $72.5 \pm 2.3-73.3 \pm 5.9 \%$ and $88.9 \pm 3.9-92.9 \pm 3.5 \%$ compared with the control group infected with J2s, respectively. In particular, this combination considerably improved the dry weight of roots and shoots compared with those of the group treated with fosthiazate alone (Table 2).

\section{Analysis of Microbial Changes in Soil Treated with KRA-24 and KRA-28}

We also measured the change in the number of total bacteria and actinomycetes in the soils treated with $S$. misionensis KRA-24 and S. yatensis KRA-28. In the control group infected with J2s, the number of initial bacteria was approximately $10^{3}$ and increased by 10 - and 100 -fold after 30 and 60 days, respectively. Compared with the control group infected with $\mathrm{J} 2 \mathrm{~s}$, the number of bacteria in the group treated with fosthiazate decreased by approximately 100 -fold after 30 and 60 days. Additionally, the total number of bacteria in the group treated with KRA-24 or KRA-28, compared to that in the control group infected with J2s, decreased by approximately 10 -fold. Table 4 shows that there was no significant difference in the number of bacteria in the microbe-treated groups and those treated with both fosthiazate and KRA-24 or KRA-28. This result showed that the KRA-24 or KRA-28 strains can survive in soil for a long time without being affected by fosthiazate.

\section{Discussion}

The most commonly used method to control root-knot nematodes is the application of chemicals, such as fosthiazate, terbufos and ethoprophos. However, the use of chemical agents is limited due to their ability to cause human toxicity, soil pollution, water pollution, and the emergence of resistant bacteria [12]. Biological agents that control nematodes have been actively searched for in recent years, and several plant extracts and microorganisms have been successfully applied to plant roots $[9,10,22]$. However, these approaches have been less effective than organic synthetic pesticides, and these biocontrol agents are less widely available as eco-friendly controls. Biological control agents, such as Myrtus communis, Nepeta cataria, Tagetes patula, Zoysia japonica, Rhus sylvestris, Rhus chinensis and Allium cepa have been useful in managing root-knot nematodes [10,23,24]. Additionally, several microorganisms, such as Paenibacillus lentimorbus, P. polymyxa, Bacillus thuringiensis, B. megaterium, Trichoderma harzianum and Streptomyces spp. have been used to study nematode control [19, 25-28]. Streptomyces spp., including S. cacaoi, S. avermitilis, and S. hydrogenans have been particularly used to control plant parasitic nematodes in many studies $[12,14,29]$ because they produce large amounts of antibiotic compounds, including streptomycin, neomycin, fosfomycin, tetracycline, kanamycin, and vancomycin. Therefore, there is a need to develop biological agents using microorganisms that have no serious chemical risks and have a good impact on soil and crops.

In our present study, we identified a novel Streptomyces strain with excellent anti-nematode activity that is applicable to environmentally friendly agriculture. As a result of screening for anti-nematode activity, two strains, KRA-24 and KRA-28, were observed to cause 85.9 and $75.9 \%$ mortality rates of J2s after a 48 h incubation, respectively. Additionally, the culture broth of KRA-28 strain showed dose-dependent anti-nematode activity and an approximately $10 \%$ higher anti-nematode activity than that of KRA-24 (Fig. 2). These strains were identified as Streptomyces misionensis KRA-24 and Streptomyces yatensis KRA-28 by analyzing their 16 S ribosomal RNA gene sequences. Two strains were selected for study because they may behave differently when applied to fields, and we conducted pot experiments to confirm that both microorganisms were applicable as biological control agents. When soil is infected by root-knot nematodes, most farmers will use chemical agents to temporarily control the parasites. Accordingly, we conducted experiments to confirm whether these strains were resistant to chemical agents such as fosthiazate. As shown in Table 1, the strains were not greatly influenced by the recommended concentration $(0.1 \%)$ for use of each chemical agent, and their growth was also not greatly affected at a concentration of $0.5 \%$. When the group treated with microorganisms alone and the group treated with both microorganisms and chemical agent are compared (Tables 1-4), the results show that the growth of 
microorganisms treated in the early stages was unaffected by the chemical agent. Chemical agents containing fosthiazate are generally used at $0.1 \%$ concentrations (for nematode control) in greenhouses, but based on the results in this study using red pepper plants (Table 2), the recommended concentration of this agent (0.1\%) negatively affected the growth rate of crops. However, treatment with the S. misionensis KRA-24 or S. yatensis KRA-28 strain with fosthiazate improved the plant growth over treatment with fosthiazate alone. That is, these strains can be effectively used because they can reduce the growth inhibition effect of chemical agents on the crops without affecting the anti-nematode activity of the chemical agent (Tables 2 and 3 ). These results demonstrate that these strains can be used with pesticides or can survive in soil where pesticides are present. Recently, Huang et al. (2016) reported that using a combination of Syncephalastrum racemosum and Paecilomyces lilacinus reduced the number of nematodes and the amount of root galling by Meloidogyne incognita and increased the root length, shoot length and plant weight of cucumber plants compared with an untreated control group. Additionally, Kaur et al. (2016) observed that culture filtrate of Streptomyces hydrogenans DH16 and metabolites produced by this strain inhibited hatching of $M$. incognita J2s and killed hatched juveniles. Furthermore, the culture supernatant and cells of this strain effectively controlled root galls and egg masses in nematode-infested tomato plants. However, these two studies were conducted to confirm the inhibition of the nematode activity by pretreatment or simultaneous treatment with microorganisms. Instead, we first confirmed that egg masses formed after infecting the crops with root-knot nematodes, after which we conducted an experiment to verify whether these strains inhibited secondary infection by root-knot nematodes that had hatched from the egg masses. S. yatensis KRA-28 was more effective than KRA-24 in reducing the numbers of nematodes and egg masses, and the KRA-28 strain, compared with the KRA-24 strain, greatly enhanced shoot length and dry weight. As a result, we will conduct research on whether $S$. yatensis KRA-28 can be used as a biological control agent in the future.

In conclusion, 30 Streptomyces spp. strains isolated from Mt. Naejang soil were tested in larvicidal assay using M. incognita, and the culture broth of the KRA-28 strain, compared with that of other strains, exhibited excellent insecticidal activity. This strain reduced the number of nematodes in the soil and the number of egg masses on red pepper roots in pot experiments. Additionally, KRA- 28 strain survived in the presence of insecticide agents ( 0.1 to $3.0 \%$ ) such as fosthiazate, ethoprophos and terbufos. In future investigations, we will conduct safety and field experiments to test $S$. yatensis KRA-28 as a new biocontrol agent against Meloidogyne incognita.

\section{Acknowledgments}

This research was financially supported by the Agricultural Bio-industry Technology Development Program of the Ministry of Agriculture, Food, and Rural Affairs (115088-2) and a grant from the KRIBB Research Initiative Program (KGS1002012).

\section{Conflict of Interest}

The authors have no financial conflicts of interest to declare.

\section{References}

1. Geeta S. 2004. Biocontrol of nematode-borne diseases in vegetable crops. pp. 397-450. In: Mukerji KG (ed.), Fruit and vegetable diseases, Kluwer Academic Publishers, USA.

2. Kim DG, Lee JH. 2008. Allium tuberosum, a new host of root-knot nematode, Meloidogyne incognita in Korea. Res. Plant Dis. 14: $76-$ 78 .

3. Kim DG, Kim HS, Kim SH, Lee JH, Yoon JT. 2004. Occurrence of root-knot nematode on Dendranthema $\mathrm{x}$ grandiflorum and influences Korean J. Appl. Entomol. on plant growth. Res. Plant Dis. 10: 25-29.

4. Cho MR, Lee BC, Kim DS, Jeon HY, Yiem MS, Lee JO. 2000. Distribution of plant-parasitic nematodes in fruit vegetable production areas in korea and identification of root-knot nematodes by enzyme phenotypes. Korean J. Appl. Entomol. 39: 123-129.

5. Kim DG, Lee YK, Park BY, 2001. Root-knot nematode species distributing in greenhouses and their simple identification scheme. Res. Plant Dis. 7: 49-55.

6. Tariq M, Muneeba A, Muhammad A, Asim G, 2017. Resistance evaluation and host status of selected green gram germplasm against Meloidogyne incognita. Crop Protect. 92: 198-202.

7. Kim JI, Han SC, 1988. Effect of solarization for control of root-knot nematode (Meloidogyne spp.) in vinyl house. Korean J. Appl. Entomol. 27: 1-5.

8. Park SD, Park SD, Kwon TY, Choi BS, Lee WS, Choi YE. 1995. Study on intergrated control against root-knot nematode of fruit vegetables (Oriental Melon and Cucumber) in vinyl house. 34: 75-81.

9. Huang WK, Cui JK, Liu SM, Kong LA, Wu QS, Peng H, et al. 2016, Testing various biocontrol agents against the root-knot nematode (Meloidogyne incognita) in cucumber plants identifies a combination of Syncephalastrum racemosum and Paecilomyces lilacinus as being most effective. Biol. Control 92: 31-37.

10. Kaura T, Jasrotiab S, Ohrib P, Manhas RK. 2016. Evaluation of in vitro and in vivo nematicidal potential of a multifunctional streptomycete, Streptomyces hydrogenans strain DH16 against Meloidogyne incognita. Microbiol. Res. 192: 247-252.

11. Pavaraj M, Bakavathiappan G, Baskaran S. 2012. Evaluation of some plant extracts for their nematicidal properties against root-knot nematode, Meloidogyne incognita. J. Biopest. 5: 106-110.

12. Thomason IJ. 1987. Challenges facing nematology: environmental risk with nematicide and the need for new approaches. pp. 469479. In: Veech JA, Dickson DW (eds.), Vistas on nematology. Society of Nematologists, Havattsville, M.D, USA

13. Kaur T, Manhas RK. 2014. Antifungal, insecticidal, and plant growth promoting potential of Streptomyces hydrogenans DH16. J. Basic Microbiol. 54: 1175-1185.

14. Yoon GY, Lee YS, Lee SY, Park RD, Hyun HN, Nam Y, et al. 2012. Effects on Meloidogyne incognita of chitinase, glucanase and a secondary metabolite from Streptomyces cacaoi GY525. Nematology 14: 175-184.

15. Ruanpanun P, Laatsch H, Tangchitsomkid N, Lumyong S. 2011. Nematicidal activity of fervenulin isolated from a nematicidal actinomycete, Streptomyces sp. CMU-MH021, on Meloidogyne incognita. World J. Microbiol. Biotechnol. 27: 1373-1380.

16. Casey JT, Walsh PK, O'Shea DG. 2007. Characterisation of adsorbent resins for the recovery of geldanamycin from fermentation broth. Sep. Purif. Technol. 53: 282-288. 
17. Kim KH, Joe YA, Choi SR, Goo YM. 1989. Comparative studies on Streptomycin producing strains and media. Korean J. Biotechnol. Bioeng. 4: 162-166.

18. Moon HS, Khan Z, Kim SG, Son SH, Kim YH. 2010. Biological and structural mechanisms of disease development and resistance in chili pepper infected with the root-knot nematode. Plant Pathol. J. 26: 149-153.

19. Khan Z, Kim SG, Jeon YH, Khan HU, Son SH, Kim YH. 2008. A plant growth promoting rhizobacterium, Paennibacillus polymyxa strain GBR-1, suppresses root-knot nematode. Bioresour. Technol. 99: 3016-3023.

20. Son SH, Khan Z, Kim SG, Kim YH. 2009. Plant growth-promoting rhizobacteria, Paenibacillus polymyxa and Paenibacillus lentimorbus suppress disease complex caused by root-knot nematode and fusarium wilt fungus. J. Appl. Microbiol. 107: $524-532$.

21. Goodell PB, Ferris H. 1989. Influence of environmental factors on the hatch and survival of Meloidogyne incognita. J. Nematol. 21: 328-334.

22. Kaya HK, Stock SP. 1997. Techniques in insect nematology. Manual of techniques in insect pathology. 1: 281-324.

23. Oka Y, Ben-Daniel B, Cohen Y. 2012. Nematicidal activity of the leaf powder and extracts of Myrtus communis against the root-knot nematode Meloidogyne javanica. Plant Pathol. 61: 1012-1020.

24. Kim HH, Choo HY, Park CG, Lee SM, K JB. 1998. Biological control of the northern root-knot nematode, Meloidogyne hapla with plant extract. Korean J. Appl. Entomol. 37: 199-206.

25. Ruanpanum P, Laatsch H, Tangchitsomkid N, Lumyong S. 2011. Nematicidal activity of fervenulin isolated from a nematicidal actinomycete, Streptomyces sp. CMU-MH021, on Meloidogyne incognita. World J. Microbiol. Biotechnol. 27: 1373-1380.

26. Sharon E, Bar-Eyal M, Chet I, Herrera-Estrella A, Kleifeld O, Spiegel Y. 2001. Biological control of the root-knot nematode Meloidogyne javanica by Trichoderma harzianum. Phytopathology 91: 687-693.

27. Mohammed SH, El Saedy MA, Enan MR, Ibrahim NE, Ghareed A, Moustafa SA. 2008. Biocontrol efficiency of Bacillus thuringiensis toxins against root-knot nematode, Meloidogyne incognita. J. Cell Mol. Biol. 7: 57-66.

28. Padgham JL, Sikora RA. 2007. Biological control potential and modes of action of Bacillus megaterium against Meloidogyne graminicola on rice. Crop Protect. 26: 971-977.

29. Jayakumar J. 2009. Bio-efficacy of Streptomyces avermitilis culture filtrates against root knot nematode, Meloidogyne incognita and reniform nematodes, Rotylenchulus reniformis. Karnataka J. Agric. Sci. 22: 567-571. 